\title{
A Radiological Investigation on the Hand Development in Human Fetuses Throughout the Fetal Period and an Evaluation Performed in Terms of its Clinical Importance Hand Development
}

\author{
Investigación Radiológica Sobre el Desarrollo de la Mano en Fetos Humanos a lo Largo del Período \\ Fetal y una Evaluación Realizada en Términos de su Importancia Clínica en el Desarrollo de la Mano
}

\author{
Desdicioglu Raziye*; Uguz Ceren"*; Desdicioglu Kadir***; Sulak Osman ${ }^{* * * * *} \&$ Malas Mehmed Ali ${ }^{* * * * * *}$
}

RAZIYE, D.; CEREN, U.; KADIR, D.; OSMAN, S. \& MEHMED ALI, M. A Radiological investigation on the hand development in human fetuses throughout the fetal period and an evaluation performed in terms of its clinical importance. Int. J. Morphol., 34(4):1539$1552,2016$.

SUMMARY: It was aimed in this study that the morphometric development of the hand in human fetuses throughout the fetal period be radiologically investigated and the clinical importance of this period be evaluated. A total of 50 fetuses with no external pathology or anomaly, and the ages of which varied between 20-40 gestational weeks were incorporated into the study. The fetuses were separated into groups according to gestational weeks, trimesters and months. After the general external measurements of the fetuses were performed, mammography and hand radiographies of the fetuses were shot in the way that their hands would be in a pronational position. Afterwards, the morphometric measurements of the hands were performed with the help of a digital caliper through the hand radiographies that were shot. The averages and standard deviations of the measured parameters were determined according to gestational weeks, trimesters and months. There was a significant correlation between the measured parameters and the gestational age ( $\mathrm{p}<0.001)$. Additionally, it was observed that there was some difference among the groups in the comparison of the measured parameters involving trimesters and months $(\mathrm{p}<0.05)$. We are of the opinion that in evaluating the clinical studies regarding the morphometric development of the hand throughout the fetal period and in determining the pathologies and variations related to the fetal hand development, the data obtained in our study will be of use to the clinicians engaged in gynecology, and forensic medicine as well as those involved in this field.

KEY WORDS: Fetus; Hand; Fetal development; Morphometry; Radiology.

\section{INTRODUCTION}

The fetal period that lasts from the 9 th week of gestation up until the delivery is the phase during which the fetus rapidly grows and the organs are formed (Sadler, 1990; Williams et al., 1995). The prenatal analysis of the fetal bones through ultrasonography provides information as to the fetal growth and gestational age (Taeusch, 1991). The development of the skeletal system, as in other systems, takes place in a certain order (Moore \& Persaud, 2008). While the upper extremities begin to develop between 26th -27 th days of gestation, the hands and fingernails begin to develop within the 21st and 24th weeks of gestation (Malas et al., 2006; Sadler). The malformations seen in the extremities during the fetal period take shape in the form of external images of several syndromes (Sadler; Williams et al.). Thus, it is important to perform an ultrasonographic evaluation of fetal hands and feet for the antenatal diagnoses of gestations with high risk, since hand and foot anomalies often accompany fetal trisomy syndromes. The most frequently observed digit anomaly is polydactyly, which occurs in Trisomy 13 syndrome. Again, ultrasonographically, some findings, such as limb reduction and club or rocker-bottom feet are seen in Trisomy 18 syndrome (Hata et al., 1998). Separately, it is emphasized that the findings, such as the shortness and curling in the mid-phalanx of the 5th digit during the prenatal period, are specific findings for Down's syndrome (Hata et al.; Kjaer et al., 1998). Again, hand radiographies are used for

Yıldırım Beyazıt University, Medical Faculty, Department of Obstetrics and Gynecology, Ankara-Turkey.

** Mugla Sitkı Kocman University, Medical Faculty, Department of Anatomy, Mugla-Turkey.

*** Yildırım Beyazıt University, Medical Faculty, Department of Anatomy, Ankara-Turkey.

**** Suleyman Demirel University, Medical Faculty, Department of Anatomy, Isparta-Turkey.

${ }^{* * * * * *}$ Izmir Katip Celebi University, Medical Faculty, Department of Anatomy, Izmir-Turkey. 
RAZIYE, D.; CEREN, U.; KADIR, D.; OSMAN, S. \& MEHMED ALI, M. A Radiological investigation on the hand development in human fetuses throughout the fetal period and an evaluation performed in terms of its clinical importance. Int. J. Morphol., 34(4):1539-1552, 2016.

determining the body height and age as well as evaluating the development and the maturation of the skeletal system during the postnatal period (Kjaer \& Kjaer, 1998). Furthermore, in the assay of the bone age of the children aged between 3-19 (Martin et al., 2011).

There are a number of ultrasonographic studies conducted to determine the delay of fetal development, fetal weight and fetal age and to evaluate the fetal extremity development during the gestational period (Stoll et al., 1994; Hata et al.; Czerwinski et al., 2004). Martin et al.. examined the thickness, width, length and medullar diameter of metacarpal bones in the children aged between 3-19. They state the fact that the data they obtained as the result of the study will be the basis for the studies to be conducted as regards bone development as well as the management of hormonal therapy in children. Kjaer \& Kjaer conducted a radiological study regarding the hand development during the fetal period between 10th-23rd gestational weeks. They state that the data they obtained as the result of their study will be of use in terms of evaluating the pathologies related to hand development. Kjaer et al.. evaluated the hand development and maturation in the patients with Trisomy-21 during the fetal period. As the result of their evaluation, they emphasize the fact that the hand length was normal, the third digit was short and that the mid-phalanx of the fifth digit had ossified late in terms of development. Uluutku et al.. (2010) as the result of the study they conducted, state that hand length is of importance in the assay of gestational age.

In humans, the features specific to an individual, such as the proportion of each limb and its shape, actually contain important information about that individual. As the result of extensive literature studies, it is reported that by obtaining information from the digit proportion of a certain individual, several important information may be revealed with respect to the life, health and personal preferences of that individual (Malas et al.; Schwerdtfeger et al., 2010). Therefore, several scientific studies have been conducted on the ratio of index finger to the ring finger (2D:4D) (Malas et al.; Schwerdtfeger et al.). According to the result of the study conducted on surgeons; it is stated that $2 \mathrm{D}: 4 \mathrm{D}$ digit ratio in male surgeons proved to be significantly lower than that in the control group, whereas this ratio was not different between the female surgeons and the control group (Joyce et al., 2014). In some conducted studies, it is also reported that the bone development during the fetal period is associated with hormones and that this association indicated to several diseases (Manning et al., 1998; Robinson \& Manning, 2000). Robinson \& Manning expresses the fact that estrogen showed a positive correlation, whereas testosterone showed a negative correlation in 2D:4D digit ratio. Brown et al.. (2002) in their study conducted on the 2D:4D digit ratio in the patients with congenital adrenal hyperplasia $(\mathrm{CAH})$, state that 2D:4D digit ratio on the left hand of male patients was smaller, whereas this ratio was smaller on the right hand of female patients when compared with the patients who had no congenital adrenal hyperplasia. Buck et al.. (2003) in a similar study they conducted, compared 2D:4D digit ratio in male and female patients with $\mathrm{CAH}$ and found that 2D:4D digit ratio proved to be smaller in male patients. Separately, it is pointed out that 2D:4D digit ratio did not differ in females in terms of sexual orientation, whereas this ratio differed in males in terms of sexual orientation (between homosexuals and heterosexuals) (Manning et al., 2007).

In our study, different from the others, we aimed to radiologically investigate the development of hand during the fetal period between 20-40 weeks in human fetuses as well as evaluating its clinical importance.

\section{MATERIAL AND METHOD}

The study comprised of 100 fetuses hand (50 fetuses: 23 males, 27 females) at a gestational age of 20-40 weeks; the fetuses were obtained from the prenatal period or after abortion. In order to use the fetuses as experimental materials, the signed consents were obtained from the families and the experimental procedures were ethically approved by the official laws and regulations of Turkish Ministry of Health. The fetuses with external pathology or anomalies and those cases with anomalies (omphalocel, gastroschisis, diaphragm hernia, Meckel diverticulum, colon malposition, renal agenesis, ectopic kidneys, agenesis of external genitalia, etc.) were also not studied.

Gestational ages of the fetuses were determined using crown-rump length (CRL), bi-parietal diameter (BPD), head circumference (HC), femur length (FL) and foot length (Moore \& Persaud). Fetuses were assigned to one of three groups according to their gestational ages: Group I (2nd trimester, 20-25 weeks), Group 2 (3rd trimester, 26-37 weeks) and Group 3 (term, 38-40 weeks). Fetuses were also divided into 6 groups according to their gestational age in months; fetuses aged 20, 21-24, 25-28, 29-32, 33-36, and 37-40 weeks were assigned to $5,6,7,8,9$, and 10-months groups, respectively.

Afterwards, the mammographies and radiographies of the hands of fetuses were shot in the way that they would be in a pronational position (Fig. 1). The radiographies that were shot were placed on the negatoscope, and the morphometric measurements were performed with the help of a digital caliper by starting from the radial part of the hand. 


\section{Morphometric Measurements Performed:}

1st Metacarpal Length $(\mathrm{MiL})$ : The vertical distance between the starting point and the end point of the metacarpal bone.

1st Metacarpal Proximal Width (MiPW): The transverse width of the proximal region of 1 st metacarpal bone.

1st Metacarpal Distal Width (MiDW): The transverse width of the distal region of 1 st metacarpal bone.

2nd Metacarpal Length $\left(\mathrm{M}_{11} \mathrm{~L}\right)$ : The vertical distance between the starting point and the end point of 2 nd metacarpal bone.

2nd Metacarpal Proximal Width (Mi1PW): The transverse width of the proximal region of 2nd metacarpal bone.

2nd Metacarpal Distal Width (Mi1DW): The transverse width of the distal region of 2nd metacarpal bone.

3rd Metacarpal Length $\left(\mathrm{M}_{111 \mathrm{~L}}\right)$ : The vertical distance between the starting point and the end point of 3rd metacarpal bone.

3rd Metacarpal Proximal Width (M111PW): The transverse width of the proximal region of 3rd metacarpal bone.

3rd Metacarpal Distal Width (M111DW): The transverse width of the distal region of 3rd metacarpal bone.

4th Metacarpal Length (MivL): The vertical distance between the starting point and the end point of 4th metacarpal bone.

4th Metacarpal Proximal Width (MivPW): The transverse width of the proximal region of 4 th metacarpal bone.

4th Metacarpal Distal Width (MivDW): The transverse width of the distal region of 4th metacarpal bone.

5th Metacarpal Length $(\mathrm{MvL})$ : The vertical distance between the starting point and the end point of 5th metacarpal bone.

5th Metacarpal Proximal Width (MvPW): The transverse width of the proximal region of 5 th metacarpal bone.

5th Metacarpal Distal Width (MvDW): The transverse width of the distal region of 5th metacarpal bone.

1st Proximal Phalanx Length ( $\mathrm{PP} 1 \mathrm{~L})$ : The vertical distance between the starting point and the end point of the proximal phalanx belonging to the 1st digit.

1st Proximal Phalanx Proximal Width (PP1PW): The transverse width of the proximal region of the proximal phalanx belonging to the $1 \mathrm{st}$ digit.

1st Proximal Phalanx Distal Width (PPiDW): The transverse width of the distal region of the proximal phalanx belonging to the 1st digit.

1st Distal Phalanx Length (DPIL): The vertical distance between the starting point and the end point of the distal phalanx belonging to the 1st digit.

1st Distal Phalanx Proximal Width (DPiPW): The transverse width of the proximal region of the distal phalanx belonging to the $1 \mathrm{st}$ digit.

1st Distal Phalanx Distal Width (DP1DW): The transverse width of the distal region of the distal phalanx belonging to the 1st digit.

2nd Proximal Phalanx Length $(\mathrm{PP} 11 \mathrm{~L})$ : The vertical distance between the starting point and the end point of the proximal phalanx belonging to the 2nd digit.

2nd Proximal Phalanx Proximal Width (PP11PW): The transverse width of the proximal region of the proximal phalanx belonging to the 2nd digit.

2nd Proximal Phalanx Distal Width (PP11DW): The transverse width of the distal region of the proximal phalanx belonging to the 2 nd digit.

2nd Mid-Phalanx Length (MPıL): The vertical distance between the starting point and the end point of the mid-phalanx belonging to the 2nd digit.

2nd Mid-Phalanx Proximal Width (MPıPW): The transverse width of the proximal region of the mid-phalanx belonging to the 2 nd digit. 2nd Mid-Phalanx Distal Width (MP11DW): The transverse width of the distal region of the mid-phalanx belonging to the 2 nd digit.

2nd Distal Phalanx Length (DP11L): The vertical distance between the starting point and the end point of the distal phalanx belonging to the 2 nd digit.

2nd Distal Phalanx Proximal Width (DP11PW): The transverse width of the proximal region of the distal phalanx belonging to the $2 \mathrm{nd}$ digit.

2nd Distal Phalanx Distal Width (DP11DW): The transverse width of the distal region of the distal phalanx belonging to the 2 nd digit.

3rd Proximal Phalanx Length (PP111L): The vertical distance between the starting point and the end point of the proximal phalanx belonging to the 3rd digit.

3rd Proximal Phalanx Proximal Width (PP111PW): The transverse width of the proximal region of the proximal phalanx belonging to the 3rd digit.

3rd Proximal Phalanx Distal Width (PP111DW): The transverse width of the distal region of the proximal phalanx belonging to the $3 \mathrm{rd}$ digit.

3rd Mid-Phalanx Length (MP111L): The vertical distance between the starting point and the end point of the mid- phalanx belonging to the 3rd digit.

3rd Mid-Phalanx Proximal Width (MP111PW): The transverse width of the proximal region of the mid- phalanx belonging to the 3rd digit. 3rd Mid-Phalanx Distal Width (MP111DW): The transverse width of the distal region of the mid- phalanx belonging to the 3rd digit.

3rd Distal Phalanx Length (DP111L): The vertical distance between the starting point and the end point of the distal phalanx belonging to the 3rd digit.

3rd Distal Phalanx Proximal Width (DP111PW): The transverse width of the proximal region of the distal phalanx belonging to the $3 \mathrm{rd}$ digit. 3rd Distal Phalanx Distal Width (DP111DW): The transverse width of the distal region of the distal phalanx belonging to the 3rd digit. 4th Proximal Phalanx Length (PPivL): The vertical distance between the starting point and the end point of the proximal phalanx belonging to the 4th digit.

4th Proximal Phalanx Proximal Width (PPivPW): The transverse width of the proximal region of the proximal phalanx belonging to the 4th digit.

4th Proximal Phalanx Distal Width (PPivDW): The transverse width of the distal region of the proximal phalanx belonging to the 4th digit. 4th Mid-Phalanx Length (MPivL): The vertical distance between the starting point and the end point of the mid-phalanx belonging to the 4 th digit.

4th Mid-Phalanx Proximal Width (MPivPW): The transverse width of the proximal region of the mid-phalanx belonging to the 4th digit. 4th Mid-Phalanx Distal Width (MPivDW): The transverse width of the distal region of the mid-phalanx belonging to the 4th digit. 4th Distal Phalanx Length (DPivL): The vertical distance between the starting point and the end point of the distal phalanx belonging to the 4th digit.

4th Distal Phalanx Proximal Width (DPivPW): The transverse width of the proximal region of the distal phalanx belonging to the 4 th digit. 4th Distal Phalanx Distal Width (DPivDW): The transverse width of the distal region of the distal phalanx belonging to the 4th digit. 5th Proximal Phalanx Length (PPvL): The vertical distance between the starting point and the end point of the proximal phalanx belonging to the 5 th digit.

5th Proximal Phalanx Proximal Width (PPvPW): The transverse width of the proximal region of the proximal phalanx belonging to the 5 th digit. 
5th Proximal Phalanx Distal Width (PPvDW): The transverse width of the distal region of the proximal phalanx belonging to the 5th digit.

5th Mid-Phalanx Length (MPvL): The vertical distance between the starting point and the end point of the mid-phalanx belonging to the 5 th digit.

5th Mid-Phalanx Proximal Width (MPvPW): The transverse width of the proximal region of the mid-phalanx belonging to the 5th digit. 5th Mid-Phalanx Distal Width (MPvDW): The transverse width of the distal region of the mid-phalanx belonging to the 5th digit.

5th Distal Phalanx Length (DPvL): The vertical distance between the starting point and the end point of the distal phalanx belonging to the 5 th digit.

5th Distal Phalanx Proximal Width (DPvPW): The transverse width of the proximal region of the distal phalanx belonging to the 5 th digit.

5th Distal Phalanx Distal Width (DPvDW): The transverse width of the distal region of the distal phalanx belonging to the 5th digit.

1st Digit Length ( $\left.\mathrm{D}_{1} \mathrm{~L}\right)$ : The vertical distance between the starting point and the end point of the 1st digit.

2nd Digit Length (D11L): The vertical distance between the starting point and the end point of the 2nd digit.

3rd Digit Length (D111L): The vertical distance between the starting point and the end point of the 3rd digit.

4th Digit Length (DivL): The vertical distance between the starting point and the end point of the 4th digit.

5th Digit Length (DvL): The vertical distance between the starting point and the end point of the 5th digit.

Hand Length (HL): The vertical distance between the transverse axis passing through the point at which the bones of the forearm end and the transverse axis passing through the extreme point of the 3 rd digit (Malas et al.).

Hand Width (HW): The widest transversing distance between 2nd and 5th digits (Malas et al.).

Hand Index: [(hand width/hand length) x 100] (Malas et al.).

2D:4D Index: [(length of 2nd digit /length of 4th digit) x 100] (Malas et al.).

Statistical Analysis. By utilizing the SPSS statistical program, the averages and standard deviations of the parameters according to sexs, gestational age and groups were ascertained. The significance level in the statistical analysis was taken as $\mathrm{p}<0.05$. The parametric values given in accordance with the groups were shown with the average \pm standard deviation. In the comparison of the groups, non-parametric tests were used due to the scarcity of the number of cases in some groups. Firstly, the Kruskall-Wallis variance analysis was performed. As the result of this analysis, the groups regarded as significant were compared in groups of twos by means of Mann-Whitney $\mathrm{U}$ test. The levels of significance were assessed through the Bonferroni Correction. The relationships between the parameters taken and the gestational age (week) were determined through the use of Pearson correlation test. In the inter-sex comparison of the parametric data, the Student- T test (in total for all the cases) and Mann-Whitney U test (within each group while comparing separately) were utilized. The values, p obtained were given in the findings section and under the tables involved.

\section{RESULTS}

The general external measurements of the fetuses were performed in the first place. It was determined in the measurements performed that there was no difference between sexs $(p>0.05)$. Afterwards, the mammographies

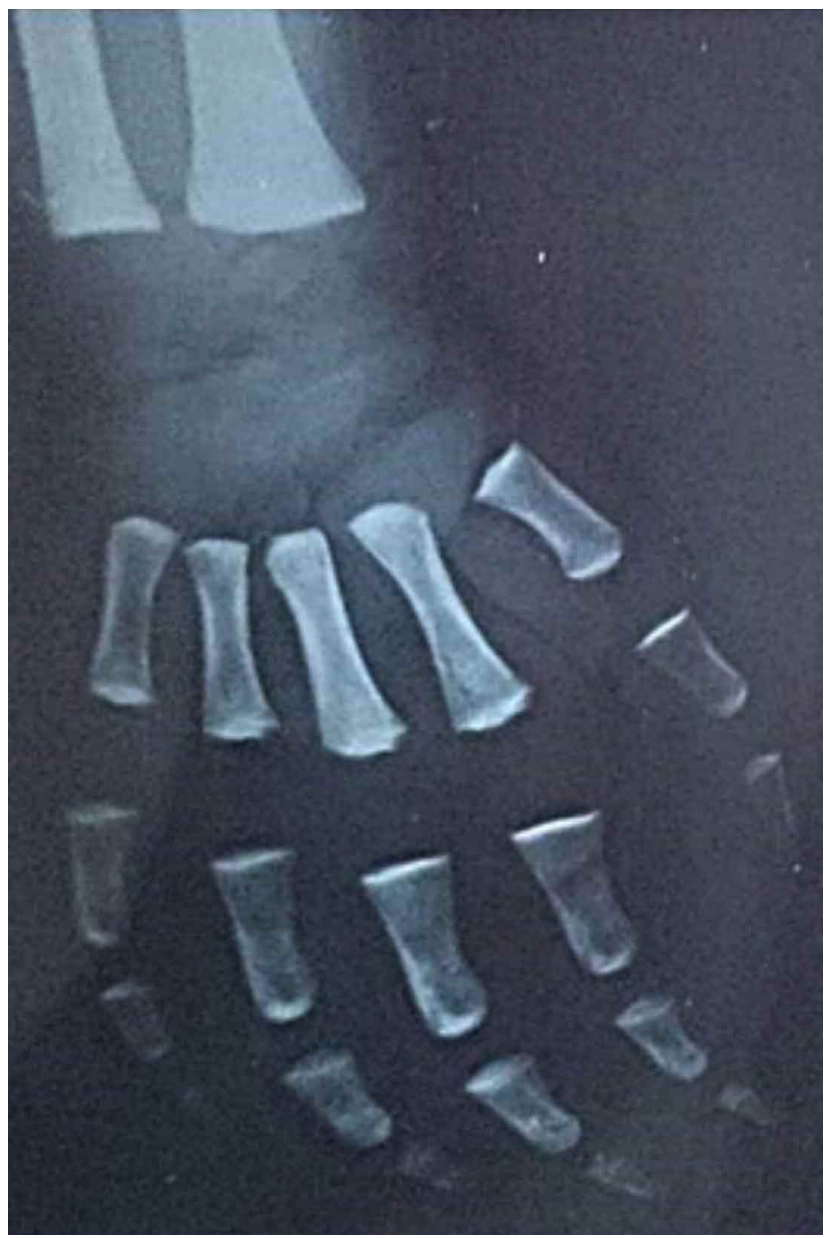

Fig. 1. The hand radiography taken from 26 week old female fetus.

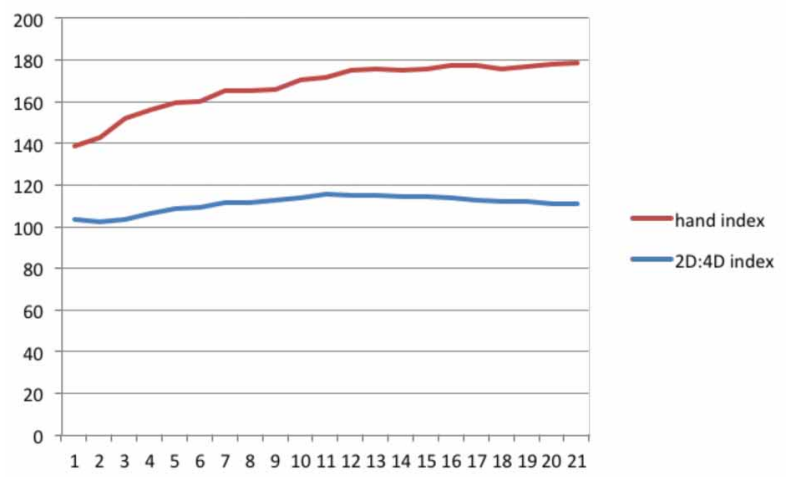

Fig. 2. The correlation of 2D:4D index with the hand index and the gestational age. 
and radiographies of the hands of fetuses were shot in the way that they would be in a pronational position (Fig. 1). According to the image results in the radiographies that were shot; it was observed that the carpal bones had not developed completely throughout the fetal period; yet, the metacarpal bone and phalanxes were seen to have developed (Fig. 1). The radiographies shot later on were placed on the negatoscope, and the morphometric measurements were performed with the help of a digital caliper by starting from the radial part of the hand. The averages and standard deviations of the morphometric measurements were determined according to weeks, trimesters and months. (Table $1 \mathrm{~A}, 1 \mathrm{~B}, 1 \mathrm{C}$, 1D, Table 2A, 2B, 2C, 2D, 2E and Table 3A, 3B, $3 \mathrm{C}, 3 \mathrm{D}, 3 \mathrm{E})$. In the comparison of these parameters in terms of trimester and monthly groups, it was observed that there was some difference between the groups $(\mathrm{p}<0.05$, Table $1 \mathrm{~A}$, 1B, 1C, 1D, Table 2A, 2B, 2C, 2D, 2E and Table 3A, 3B, 3C, 3D, 3E). Separately, in the right-left comparison and in the comparison of sexs with respect to these parameters, it was determined that there was no statistical difference $(p>0.05$, Table $1 \mathrm{~A}, 1 \mathrm{~B}, 1 \mathrm{C}, 1 \mathrm{D}$, Table 2A, 2B, 2C, 2D, 2E and Table 3A, 3B, 3C, 3D, 3E). It was ascertained that there was a significant correlation between the measured parameters and the gestational age ( $\mathrm{p}<0.001)$. In addition, 2D:4D index was reviewed in our study (Table 4A, 4B). It was determined that 2D:4D index in female fetuses proved to be higher than that in male ones; yet, no difference was detected between the sexs ( $p>0.05$, Table 4 A, 4B). As for 2D:4D index, it was determined that there was some difference between the groups in the comparison of trimester (except for the comparison between $3 \mathrm{rd}$ and 4 th trimester groups) and monthly groups $(\mathrm{p}<0.05$, Table $4 \mathrm{~A}, 4 \mathrm{~B})$. Separately, it was ascertained that the length of 2nd digit had developed more rapidly up until 30th week, whereas starting from the succeeding weeks up until the delivery, the length of 4th digit had developed more rapidly (Fig. 2, Table 4A, 4B). It was determined that there was no significant correlation between 2D:4D index and the gestational age ( $p>0.001$, Fig. 2). In addition, the hand index was reviewed in our study (Table 4A, 4B). It was observed that the hand index in female fetuses proved to be higher than that in male ones; yet, no difference was detected between the sexs ( $>0.05$, Table 4A, 4B). As for the hand index, some difference between the groups was

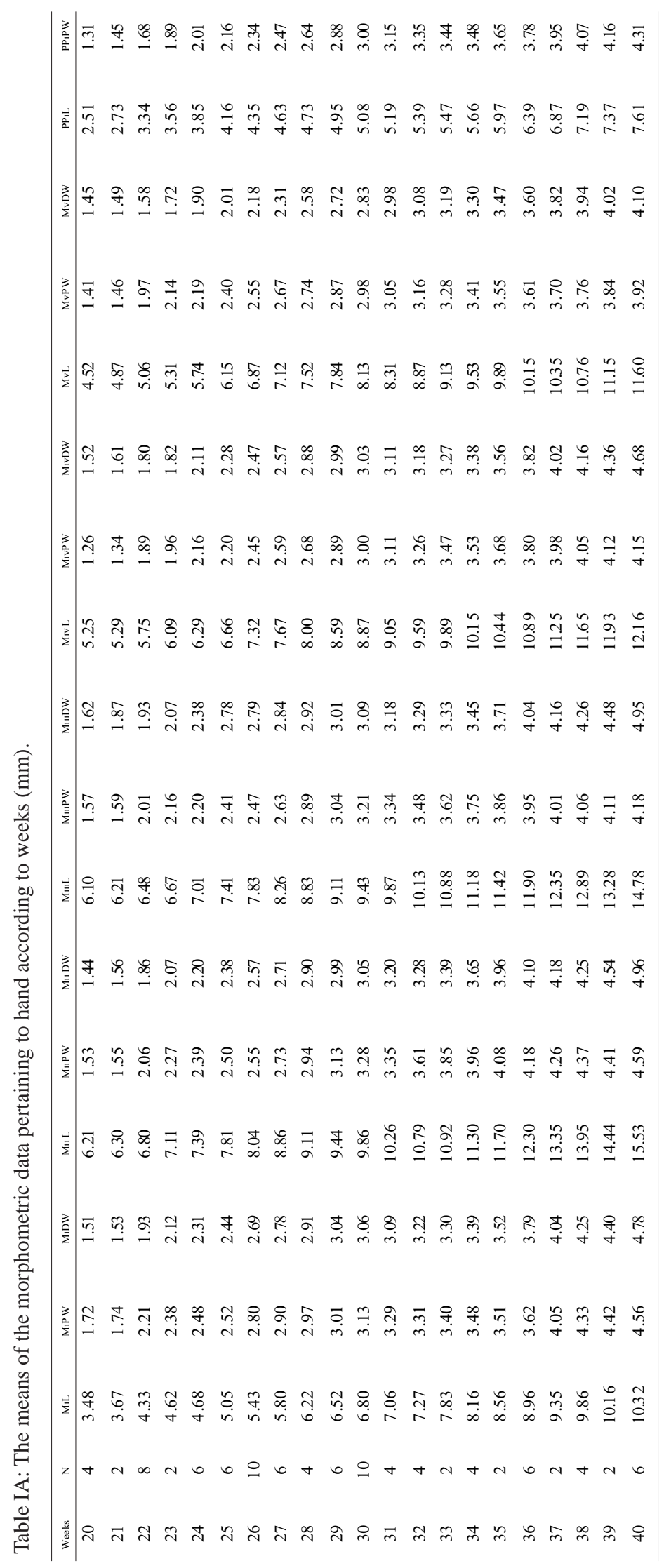


RAZIYE, D.; CEREN, U.; KADIR, D.; OSMAN, S. \& MEHMEDALI, M. A Radiological investigation on the hand development in human fetuses throughout the fetal period and an evaluation performed in terms of its clinical importance. Int. J. Morphol., 34(4):1539-1552, 2016.

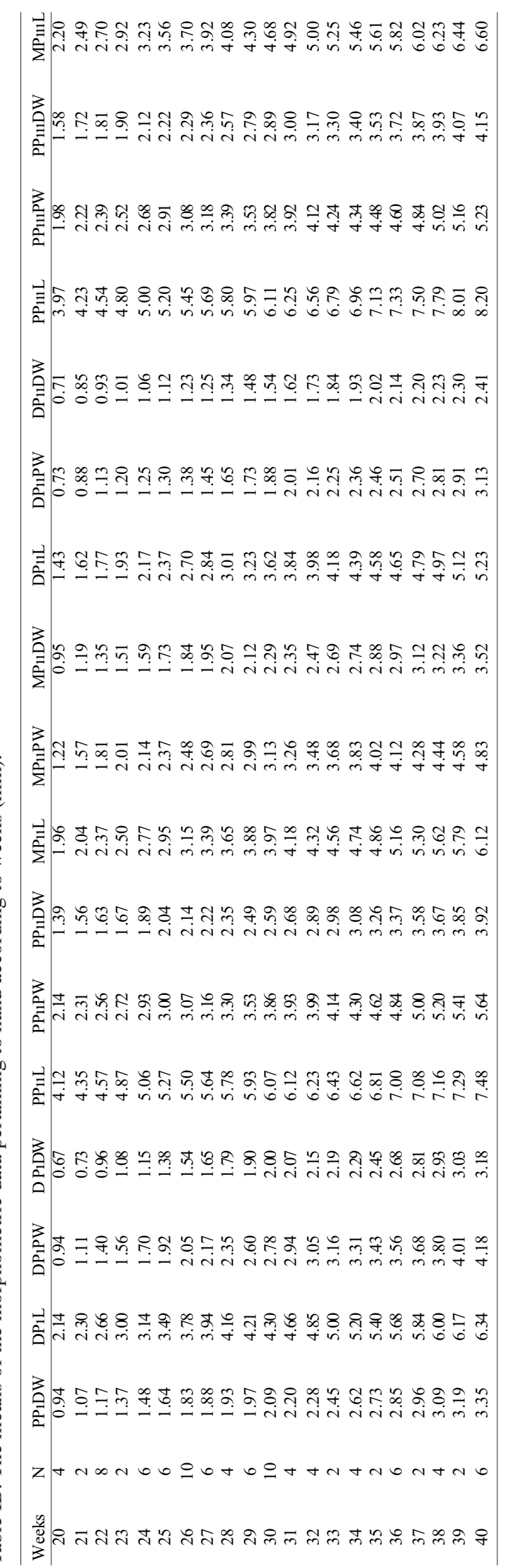

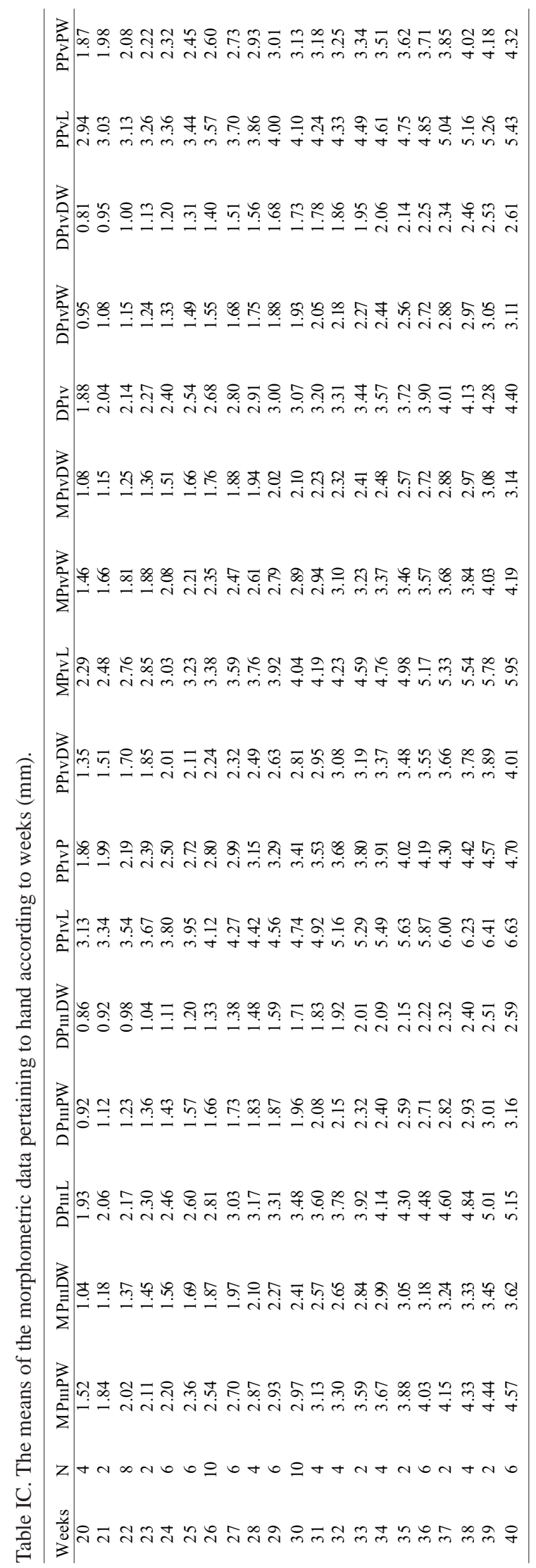



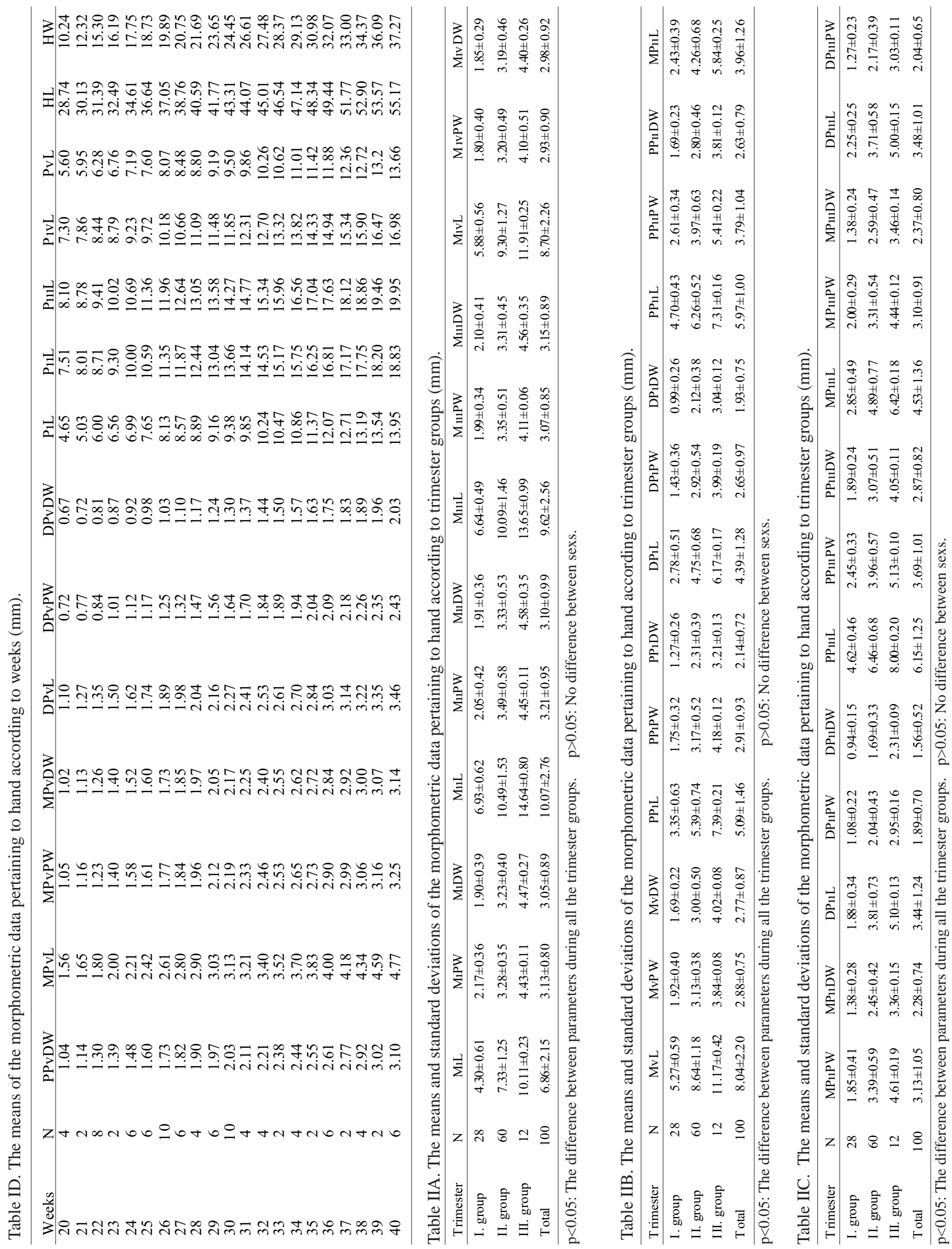

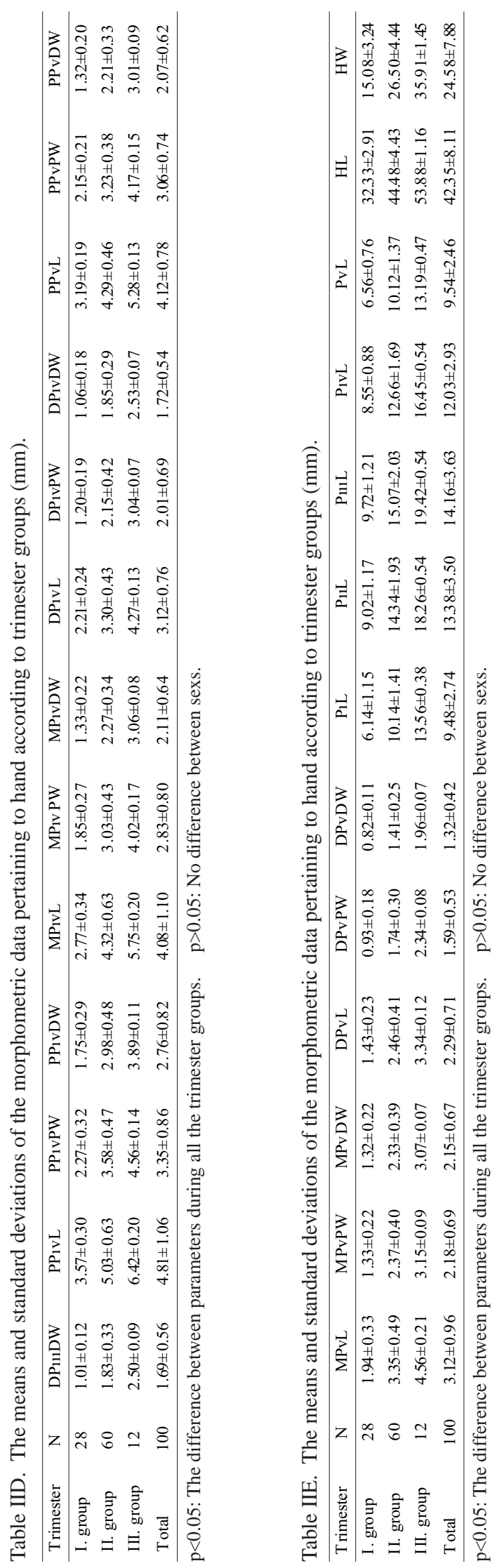

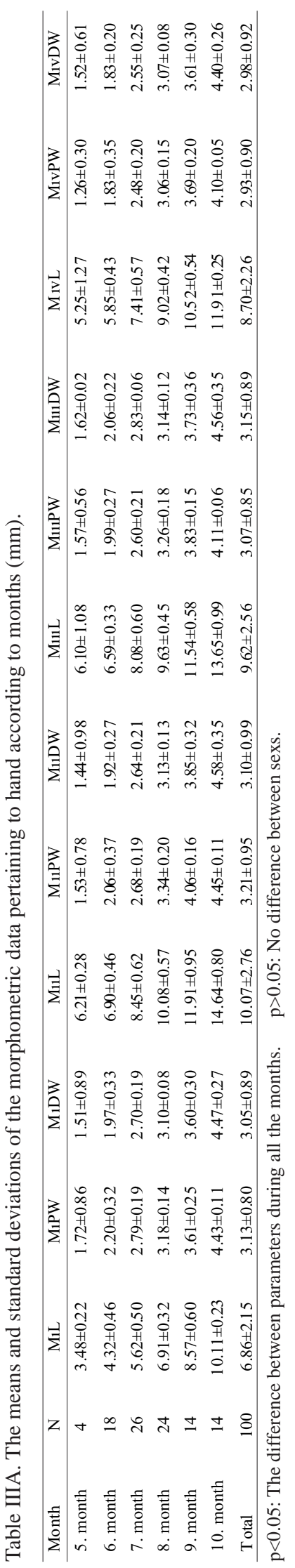

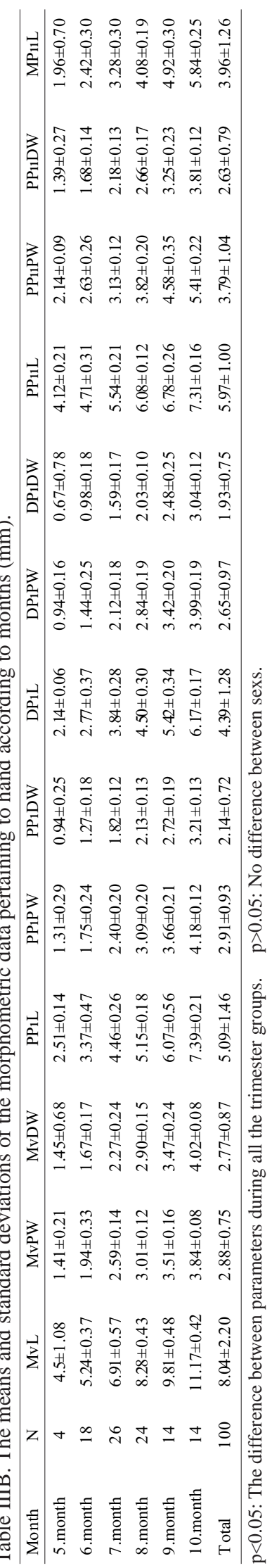


RAZIYE, D.; CEREN, U.; KADIR, D.; OSMAN, S. \& MEHMED ALI, M. A Radiological investigation on the hand development in human fetuses throughout the fetal period and an evaluation performed in terms of its clinical importance. Int. J. Morphol., 34(4):1539-1552, 2016.
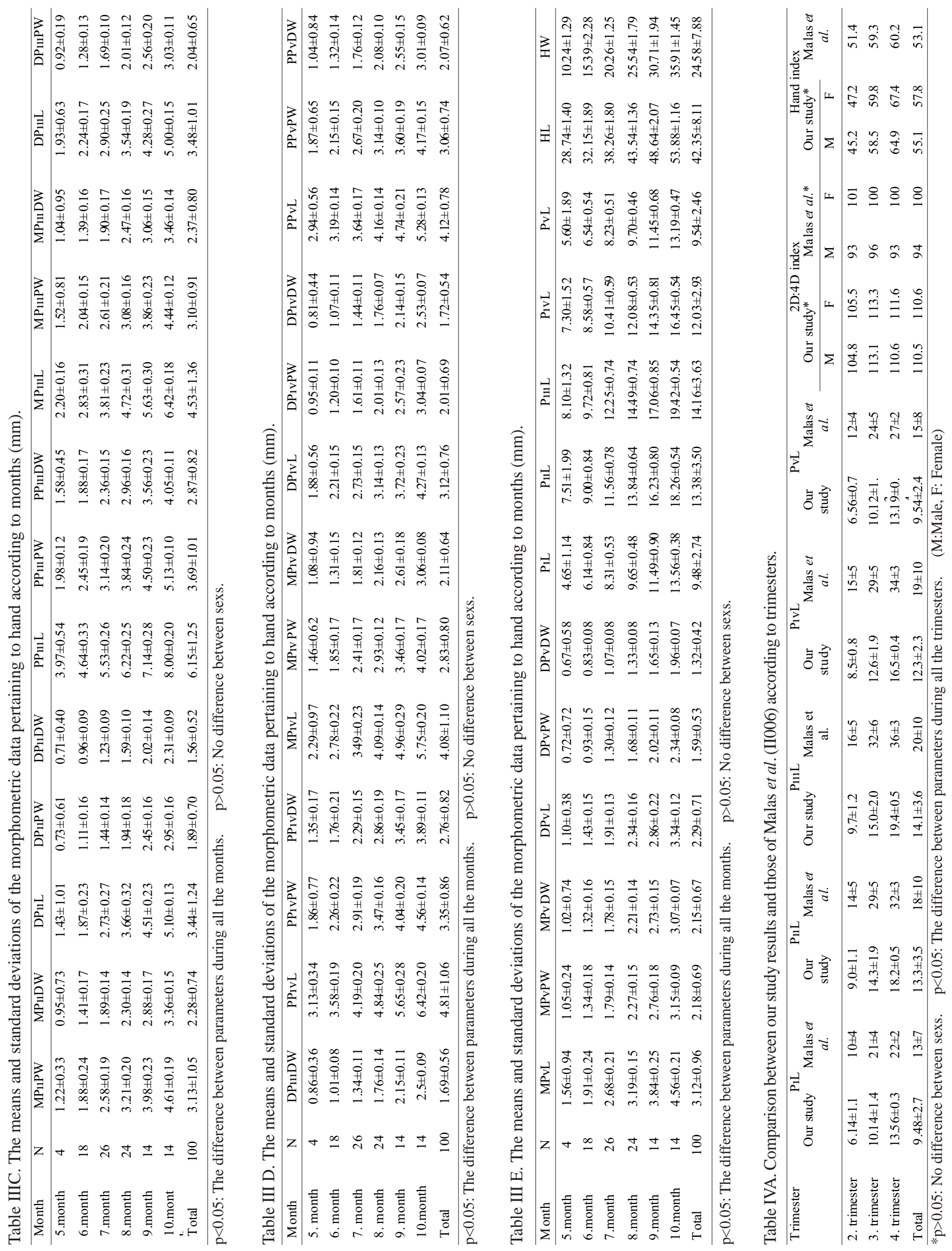


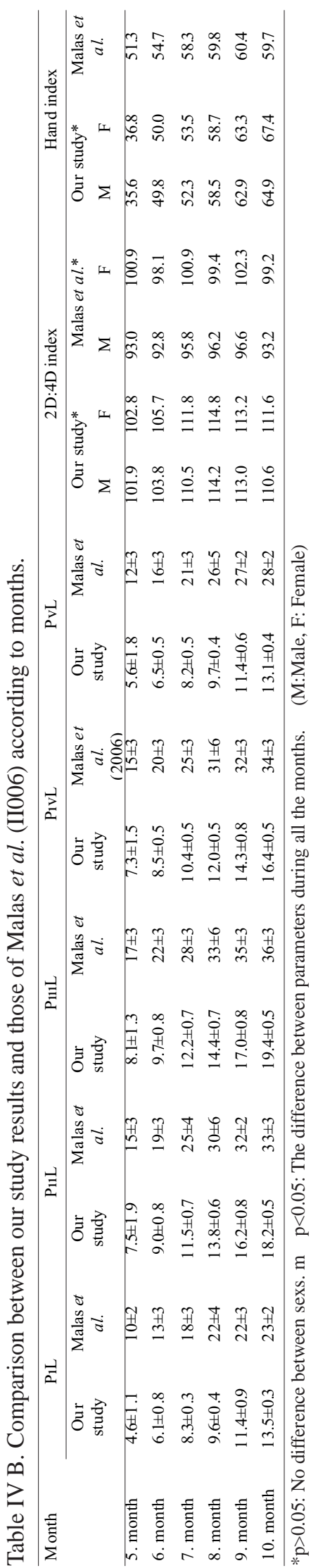

determined in the comparison of trimester and monthly groups $(\mathrm{p}<0.05$, Table $4 \mathrm{~A}$, 4B). Besides, in the hand index, it was determined that the hand width had developed more rapidly than the hand length throughout the fetal period (Fig. 2, Table 4A, 4B). A significant correlation was determined between the hand index and the gestational age ( $\mathrm{p}<0.001$, Fig. 2).

\section{DISCUSSION AND CONCLUSION}

The shape of hands and digits reflect the developmental characteristics of an individual during the prenatal and postnatal periods (Malas et al.). Separately, the prenatal analysis of fetal bones through ultrasonography provides information as to fetal growth and gestational age (Manning et al., 1998; Robinson \& Manning). For this reason, several ultrasonographic studies have been conducted on the development of fetal extremity (Budorick et al., 1998; Malas et al.). The development of the skeletal system, as in other systems, takes place within a certain order (Moore $\&$ Persaud). The malformations seen during the fetal period take shape in the form of the external images of a number of syndromes (Sadler; Williams et al.). Therefore, it is important to perform an ultrasonographic evaluation over the fetal hand and foot for the antenatal diagnosis of gestations with high risk, since hand and foot anomalies often accompany fetal trisomy syndromes (Hata et al.).

When the previous studies conducted on the development of fetal hand were reviewed, no study investigating the hand development during the fetal period through radiological methods was found. The studies conducted on the fetal period were concerned with either the histological development of hand or the morphometric hand measurements performed on cadaver fetuses (Czerwinski et al.; Kjaer \& Kjaer; Malas et al.). Besides, there were also some studies conducted on adults and Trisomy21 patients (Kjaer et al.; Martin et al.). In our study, different from the other ones, we aimed to investigate the development of hand in human fetuses over the radiological images as well as evaluating its importance in terms of clinics.

In our study, the morphometric measurements regarding length and proximal and distal regional widths of metacarpal bones were performed in the first place (Table 1A, 1B, 1C, 1D, Table 2A, 2B, 2C, 2D, 2E and Table 3A, 3B, 3C, $3 \mathrm{D}, 3 \mathrm{E})$. It was determined that there was a significant correlation between the measured parameters and the gestational age $(\mathrm{p}<0.001)$. Separately, it was determined at the end of the fetal period that $\mathrm{M}_{11} \mathrm{~L}$ had the longest and $\mathrm{M}_{1} \mathrm{~L}$ had the shortest lengths (Table 1A). It was also ascertained that the metacarpal lengths throughout the fetal period were longer in female fetuses; yet, no difference was determined between the sexs $(p>0.05$, Table 2A, 2B, Table 3A, 3B). In our study, it was observed that the measurements of the proximal and distal widths of 2 nd metacarpal bone had the highest value (Table 1A). Separately, the distal widths of the metacarpal bones were determined to be higher than the proximal ones (Table 1A). When we had a look at the studies conducted previously, we could not come across any study regarding the morphometric development of metacarpal bones during the fetal period. Czerwinski et al.. in a study they conducted, examined the ossification of metacarpal and phalangeal bones in human fetuses. As the result of the study, they state the fact that ossification started to occur in the distal phalanxes in both sexs, starting from the 5 th month onwards, whereas this process started to occur in the metacarpal bones in the 9th month. Martin et al.. in their study conducted on 231 healthy children aged between 3-19, measured the thicknesses, widths and lengths of metacarpal bones. They express that the parameters they obtained as the result of the study proved to be comparatively higher in male children according to the bone age. They also point out that the results of their study will be the basis for the forthcoming studies to be conducted on the development of the 
skeletal system and that it will also be effective on the management of the hormonal therapy to be performed on children (Martin et al.). Kjaer \& Kjaer in a study they conducted on 144 fetuses that underwent a change between 10th -23rd weeks, measured the length of the 3rd metacarpal length as well as the length of the proximal phalanx of the 3rd digit. They emphasize the fact that the data they obtained as the result of their study were important factors in the evalaution of hand length and in the assay of fetal age. Besides, they also state that this will be beneficial in the development of the skeletal system as well as the identification of pathological cases. Kjaer et al.. as the result of the study they conducted on 25 fetuses with Down syndrome, report that the 3rd metacarpal and 3rd digitproximal phalanx lengths proved to be shorter than those of the normal fetuses, whereas the hand length proved to be normal. Our study, different from the others, covers a broader part of the fetal period and yields morphometric results comprising all the metacarpal bones. We are of the opinion that the data of the results of our study will be of use in evaluating the development of the skeletal system throughout the fetal period, determining pathological cases and in identifying the fetal age and sex.

In our study, later on, the morphometric measurements were performed with respect to the digit lengths as well as the proximal, middle and distal phalanx lengths of each digit, and the widths pertaining to the proximal and distal regions of each phalanx (Table 1A, 1B, 1C, 1D, Table 2A, 2B, 2C, 2D, 2E and Table 3A, 3B, 3C, $3 \mathrm{D}, 3 \mathrm{E})$. It was determined that there was a significant correlation between the measured parameters and the gestational age $(p<0.001)$. At the end of the fetal period, it was ascertained that the $3 \mathrm{rd}$ digit was the longest and the 5 th digit was the shortest of all (Table 1A, 1B, 1C, 1D, Table 2A, 2B, 2C, 2D, 2E and Table 3A, 3B, 3C, 3D, 3E). Separately, it was determined that the data of the proximal phalanx had the highest value, whereas the data of the distal phalanx had the lowest value (Table 1A, 1B, 1C, 1D, Table 2A, 2B, 2C, 2D, 2E and Table 3A, 3B, 3C, 3D, 3E). It was also seen that the data of digit lengths and the morphometric data pertaining to phalanxes proved to be higher in female fetuses; yet, no difference was detected between the sexs (p>0.05, Table 2B, 2C, 2D, 2E and Table 3B, 3C, 3D, 3E). Malas et al.. as the result of the macroscopic study they conducted on cadaver fetuses, state the fact that the 3rd digit was the longest and the 1st digit was the shortest ones in terms of length at the end of the fetal period. They also point out that there was no difference between digit lengths in terms of sex. Again, as the result of the study, they note that there is a significant correlation between digit lengths and the gestational age. Kjaer \& Kjaer in a study they conducted on 144 fetuses that changed between 10th-23rd weeks, measured the 3rd metacarpal and 3rd digit proximal phalanx lengths. They emphasize that the data obtained as the result of the study are significant factors in determining hand length and in the identification of the fetal age, in addition to which they state that this will be beneficial in the development of the skeletal system and in determining the pathological cases. Kjaer et al.. as the result of the study they conducted on 25 fetuses with Down syndrome, report that the 3rd metacarpal and 3rd digit-proximal phalanx lengths proved to be shorter than those of the normal fetuses, whereas the hand length proved to be normal. Garn et al.. (1974) in a study they conducted on 66 embryos, the CRL of which varied between $15-75 \mathrm{~mm}$, report that the hand development in male fetuses were more rapid and that there was a statistical difference between the sexs. In the embryos, the CRL of which were 31-75 mm, however, the development in both sexs is said to be similar and there is no difference between the sexs. What distinguishes our study from others is that all the morphometric data pertaining to digits and phalanxes were obtained by using the radiological imaging method. As was seen in the study results of Malas et al.. the 3rd digit was observed as the longest one in our study, as well. While in the result of the study by Malas et al.. the 1st digit was the shortest one, in our study did the 5 th digit prove to be the shortest one. We considered the fact that this outcome was due to the direct measurement of the bone structure in the radiographies during the measurement process as well as the differences in the digit development that were likely to show up during the fetal period.

In our study, we picked the parameters pertaining to hand length and width (Table 1D, 2E and 3E). We ascertained that there was a significant correlation between the measured parameters and the gestational age $(\mathrm{p}<0.001)$. Again, during the study, we observed that hand width developed more rapidly than hand length (Fig. 2). Separately, we determined that hand width in female fetuses was larger during the fetal period when compared with that in male fetuses; yet, this was statistically insignificant ( $>0.05$, Table 4A, 4B). As for the comparison between hand length and hand width in terms of trimesters and months, we observed some difference among all groups $(\mathrm{p}<0.05$, Table $2 \mathrm{E}, 3 \mathrm{E})$. When we reviewed the former studies, we came across a study conducted on cadaver fetuses by Malas et al... Malas et al.. state as the result of their study that the hand length and width are correlated with the gestational age. Besides, in the comparison of hand length and width in terms of trimesters, some difference between the groups are mentioned. As for the comparison between months; they state that there was some difference among the other groups, except for the period between 8th-9th and 9th -10th months. Our study results, no matter how different it is in terms of the results and parameter values seen in the study results of Malas et 
al.. is still in concordance with their study in terms of the fetal development. We identified this outcome with the number of fetuses used in the study and the different materials used in the measurement process. Separately, we interpreted the study results as follows: The fetal hand length and width develops evenly between the sexs.

In our study, the hand index rate was examined later on. The hand index was determined to have been correlated with the fetal age throughout the fetal period ( $\mathrm{p}<0.001$, Fig. $2)$. In addition, the hand index was ascertained to be higher in female fetuses than in male ones; yet, this was statistically insignificant ( $p>0.05$, Table 4A, B). Separately, as for the hand index; in the comparison of the periods between the trimesters and months, some difference was identified among all groups $(\mathrm{p}<0.05$, Table $2 \mathrm{E}, 3 \mathrm{E})$. When we reviewed the former studies, we came across a study conducted on the hand index pertaining to hand development throughout the fetal period by Malas et al.. Malas et al.. as the result of their study, report that the hand index was correlated with the fetal age and that there was no difference between the sexs. Additionally, in their study, they state the fact that except for the period between 7th, 8th, 9th and 10th months, there was some difference among the other groups. Our study results show the same outcome as the results in Malas et al.. study in terms of the correlation with the fetal age and the indifference between the sexs. On the other hand, in the comparison of the periods between trimesters and months, some difference is observed in some of the groups. We identified these results with the number of fetuses used in the study and the different materials used in the measurement process. Separately, we interpreted the study results as follows: The fetal hand length and width throughout the fetal period may develop at different rates.

We reviewed 2D:4D index in our study, as well. We observed that 2D:4D index was not correlated with the fetal age throughout the fetal period ( $p>0.001$, Fig. 2). Moreover, we determined that 2D:4D index was higher in female fetuses throughout the fetal period but this did not indicate to any statistical significance ( $p>0.05$, Table 4A, 4B). In our study, we ascertained that the 2 nd digit had developed more rapidly up until the 30th week, whereas during the period that lasted from the 30th week until the delivery, the 4th digit was seen to have developed more rapidly (Fig. 2). When we reviewed the former studies concerning 2D:4D index, we came across a study conducted on human fetuses by Malas et al.. as well as other studies conducted on adults (Gorka et al., 2015; Manning et al., 2014; Manning et al., 2007; Ranson et al., 2015). Malas et al.. in their study, examined 2D:4D index throughout the fetal period and ascertained that 2D:4D index was not correlated with the fetal age. Separately, they state that this index is higher in female fetuses but does not indicate to a statistical significance. In the studies conducted on adults, however, 2D:4D index is emphasized to be higher in females (Manning et al., 2007; Joyce et al.; Manning et al., 2014; Gorka et al.; Ranson et al.). Our study results are in concordance with the other study results. We identify this outcome with the fact that the 2 nd digit develops more rapidly than the 4th digit both during the fetal period and the adulthood in females in particular. The malformations seen in the extremities during the fetal period could be the precursors of several syndromes (Sadler; Williams et al.).

Hence, it is important to perform an ultrasonographic evaluation of fetal hand and foot for the antenatal diagnosis of gestations with high risk, since hand and foot anomalies often accompany fetal trisomy syndromes. It is highlighted that the findings, such as the shortness and curling in the mid-phalanx of the 5th digit during the prenatal period, are specific findings for Down syndrome (Hata et al.; Kjaer et $a l$.). In addition, it is stated that the bone development during the fetal period is associated with the hormones and that this association is the indicator of some diseases (Manning et al., 1998; Robinson \& Manning). According to the study results performed, it is reported that estrogen shows a positive correlation, whereas testosterone shows a negative correlation in 2D:4D digit ratio (Robinson \& Manning). Besides, 2D:4D digit ratio in the patients with congenital adrenal hyperplasia was smaller on the left hand of males and on the right hand of females when compared with normal patients (Brown et al.).

Our study comprises detailed information about the radiologically morphometric development of the hand that has never been performed in former studies. We regard our study as a precursor, one which is beneficial in evaluating the development of fetal skeletal system as well as determining, at an early stage, the pathologies and anomalies as regards the development of fetal skeletal system.

In conclusion; we are of the opinion that the morphometric data obtained in our study will be of use to the involved clinicians engaged in gynecology, radiology, pathology, forensic medicine and perinatology in terms of evaluating the development of hand and the skeletal system throughout the fetal period, determining the pathologies and variations related to the development of the fetal hand and the skeletal system, and also in identifying the fetal age and sex.

\section{ACKNOWLEDGEMENTS}

We would like to express our sincere thanks to the families who have donated the fetuses to our study as well as Isparta Maternity and Paediatric Hospital that has been a mediator for the fetus donations. 
RAZIYE, D.; CEREN, U.; KADIR, D.; OSMAN, S. \& MEHMED ALI, M. Investigación radiológica sobre el desarrollo de la mano en fetos humanos a lo largo del período fetal y una evaluación realizada en términos de su importancia clínica en el desarrollo de la mano. Int. J. Morphol., 34(4):1539-1552, 2016.

RESUMEN: Se investigó radiológicamente el desarrollo morfométrico de la mano en fetos humanos a lo largo del período fetal y se evaluó la importancia clínica de este período. La muestra consistió en 50 fetos de 20 a 40 semanas de gestación, sin patología externa o anomalía. Los fetos se dividieron en grupos según las semanas, trimestres y meses de gestación. Después de las mediciones externas generales de los fetos se realizaron mamografías y radiografías de mano de los fetos en posición de pronación. Posteriormente, las mediciones morfométricas de las manos se realizaron en las radiografías con la ayuda de un calibre digital. Hubo una correlación significativa entre los parámetros medidos y la edad gestacional ( $\mathrm{p}<0,001)$. Adicionalmente, se observó que hubo una diferencia entre los grupos en la comparación de los parámetros medidos según los trimestres y meses (p <0,05). Consideramos que al evaluar los estudios clínicos sobre el desarrollo morfométrico de la mano a lo largo del período fetal y la determinación de patologías y variaciones relacionadas con el desarrollo de ésta, serán de utilidad para los clínicos intervinientes en las áreas de ginecología y medicina forense.

\section{PALABRAS CLAVE: Feto; Mano; Desarrollo fetal; Morfometría; Radiología.}

\section{REFERENCES}

Buck, J. J.; Williams, R. M.; Hughes, I. A. \& Acerini, C. L. Inutero androgen exposure and 2nd to 4th digit length ratiocomparisons between healthy controls and females with classical congenital adrenal hyperplasia. Hum. Reprod., 18(5):976-9, 2003.

Budorick, N. E.; Pretorius, D. H.; Johnson, D. D.; Tartar, M. K.; Lou, K. V. \& Nelson, T. R. Three-dimensional ultrasound examination of the fetal hands: normal and abnormal. Ultrasound Obstet. Gynecol., 12(4):227-34, 1998.

Brown, W. M.; Hines, M.; Fane, B. A. \& Breedlove, S. M. Masculinized finger length patterns in human males and females with congenital adrenal hyperplasia. Horm. Behav., 42(4):380-6, 2002.

Czerwin'ski, F.; Tomasik, E.; Tomasik, M. \& MahaczekKordowska, A. The ossification of the metacarpal and phalangeal bones in human foetuses. Folia Morphol. (Warsz.),63(3):329-32, 2004.

Garn, S. M.; Burdi, A. R. \& Babler, W. J. Male advancement in prenatal hand development. Am. J. Phys. Anthropol., 41(3):353-9, 1974.

Gorka, A. X.; Norman, R. E.; Radtke, S. R.; Carré, J. M. \& Hariri, A. R. Anterior cingulate cortex gray matter volume mediates an association between 2D:4D ratio and trait aggression in women but not men. Psychoneuroendocrinology, 56:148-56, 2015 .

Hata, T.; Aoki, S.; Akiyama, M.; Yanagihara, T. \& Miyazaki, K. Three-dimensional ultrasonographic assessment of fetal hands and feet. Ultrasound Obstet. Gynecol., 12(4):235-9, 1998.
Joyce, C. W.; Mahon, N.; Kelly, J. C.; Murphy, S.; McAllister, M.; Chan, J. C.; Kerin, M. J. \& Kelly, J. L. Hands of a surgeon: Second to fourth digit ratios in the surgical profession. Personal. Individ. Differ., 68:28-31, 2014.

Kjaer, M. S.; Keeling, J. W.; Andersen, E.; Fischer Hansen, B. \& Kjaer, I. Hand development in trisomy 21. Am. J. Med. Genet., 79(5):337-42, 1998

Kjaer, M. S. \& Kjaer, I. Human fetal hand size and hand maturity in the first half of the prenatal period. Early Hum. Dev., 50(2):193-207, 1998.

Malas, M. A.; Dogan, S.; Evcil, E. H. \& Desdicioglu, K. Fetal development of the hand, digits and digit ratio (2D:4D). Early Hum. Dev., 82(7):469-75, 2006.

Manning, J. T.; Scutt, D.; Wilson, J. \& Lewis-Jones, D. I. The ratio of 2 nd to 4th digit length: a predictor of sperm numbers and concentrations of testosterone, luteinizing hormone and oestrogen. Hum. Reprod., 13(11):3000-4, 1998.

Manning, J. T.; Churchill, A. J. \& Peters, M. The effects of sex, ethnicity, and sexual orientation on self-measured digit ratio (2D:4D). Arch. Sex. Behav., 36(2):223-33, 2007.

Manning, J.; Kilduff, L.; Cook, C.; Crewther, B. \& Fink, B. Digit ratio (2D:4D): A biomarker for prenatal sex steroids and adult sex steroids in challenge situations. Front. Endocrinol. (Lausanne), 5:9, 2014.

Martin, D. D.; Heckmann, C.; Jenni, O. G.; Ranke, M. B.; Binder, G. \& Thodberg, H. H. Metacarpal thickness, width, length and medullary diameter in children--reference curves from the First Zürich Longitudinal Study. Osteoporos. Int., 22(5):1525-36, 2011. 
RAZIYE, D.; CEREN, U.; KADIR, D.; OSMAN, S. \& MEHMED ALI, M. A Radiological investigation on the hand development in human fetuses throughout the fetal period and an evaluation performed in terms of its clinical importance. Int. J. Morphol., 34(4):1539-1552, 2016.

Moore, K. L. \& Persaud, T. V. N. The Developing Human Clinically Oriented Embryology. Philadelphia, Saunders/Elsevier, 2008.

Ranson, R.; Stratton, G. \& Taylor, S. R. Digit ratio (2D:4D) and physical fitness (Eurofit test battery) in school children. Early Hum. Dev., 91(5):327-31, 2015.

Robinson, S. J. \& Manning, J. T. The ratio of 2nd to 4th digit length and male homosexuality. Evol. Hum. Behav., 21(5):333-45, 2000 .

Sadler, T. W. Langman's Medical Embryology. 6th ed. Baltimore, Williams \& Wilkins, 1990. pp.134-40.

Schwerdtfeger, A.; Heims, R. \& Heer, J. Digit ratio (2D:4D) is associated with traffic violations for male frequent car drivers. Accid. Anal. Prev., 42(1):269-74, 2010.

Stoll, C.; Alembik, Y.; Dott, B. \& Roth, M. P. Evaluation of prenatal diagnosis of limb reduction defects by a registry of congenital anomalies. Prenat. Diagn., 14(9):781-6, 1994.

Taeusch, H. W. \& Ballord, R. A. Avery's Diseases of the Newborn. Philadelphia, W. B. Saunders Company, 1991. pp.207-24.

Uluutku, M. H.; Akbaytürk, N.; Çan, M. A. \& Özyas,ar, A. F. Gestational age and its relationship with elbow width, wrist width and forearm length. Turk. Klin. J. Med. Sci., 30(6):19938, 2010.

Williams, P. L.; Warwich, R.; Dyson, M. \& Bannister, L. H. Gray's Anatomy. 38th ed. London, Churchill Livingstone, 1995. pp.343-75.

\author{
Correspondence to: \\ Dr. Raziye Desdicioglu \\ Yıldırım Beyazıt University \\ Medical Faculty \\ Department of Obstetrics and Gynecology \\ Ankara \\ Turkey
}

E-mail: raziyedesdicioglu@gmail.com

Received: 04-03-2016

Accepted: 17-10-2016 